\title{
O PROÁLCOOL e as \\ Transformações no Espaço Agrícola da Paraíba."
}

\section{Paulo Ortiz Rocha de Aragão *" Elbio Troccoli Pakman ***}

\section{Resumo}

O objetivo deste estudo é detectar mudanças no espaço agrícola do Estado da Paraíba após o advento do Programa Nacional do Álcool (Proálcool). Vários estudos demonstram a expansão significativa do cultivo de canade-açúcar $e$ apontam profundas transformações no espaço agrícola. Este estudo destaca-se dos demais pela

) A pesquisa da qual este artigo se origina foi parcialmente financiada pelo convênio UFPb/IDRC "Estrutura Agrárla e Polftica Agrlcola na Paralba" ө também contou com $O$ apoio do CNPq, CAPES/FULBRIGHT e da Fundaçăo Tinker.

Os autores agradecem a colaboraçăo inicial da profa Maria Braga de Sá e a generosa cessão de materlais por parte do prof. Cláudio Egler, bem como a colaboração do Sindicato da Indústrla de Fabricaçăo de Álcool no Estado da Paraíba - SINDALCOOL.

* ) Professor do Departamento de Economia e Flnanças, Universidade Federal da Paralba, Campus II - Campina Grande.

* ) Professor do Departamento de Economia, Universidade Federal da Paralba, Campus I - Joåo Pessoa. 
sua metodologia. Em vez da utilização de dados agregados a nivel de micro-regióes, decidiu-se pela utilização de dados a nível municipal. Coeficientes de intensidade do cultivo de cana-de-açúcar foram computados para os principais municípios produtores de cana-de-açúcar da Paraíba. Com base nestes coeficientes e em suas taxas de mudança procura-se identificar as transformaçōes ocorridas no espaço agrícola dos municipios envolvidos, em especial identificando a área central, a periferia e o cordão externo tanto da zona canavieira tradicional (antes do Proálcool) como da nova zona canavieira (após o Proálcool)

\section{Abstract}

The objective of this study is to detect changes in the agricultural space of the state of Paraiba after the National Alcohol Program (Proálcool). Several studies have demonstrated the significant expansion of sugar cane cultivation and the profound transformations brought to the agricultural space. This study innovates in its methodology. Instead of using aggregate data at the micro-region level it uses the more precise municipal data. Intensity coefficients of sugar cane cultivation were computed for the main sugar cane producing municipality in the state of Paraiba. Based on these coefficients and on their rates of change, the transformations in the agricultural space of the municipality involved are identified: the central area, the periphery and the external belt both of the traditional sugar cane region (before Proálcool) as well as of the new sugar cane region (after Proálcool). 


\section{I - Introdução}

Este estudo procura identificar as transformaçסes no espaço agricola nos municípios paraibanos como resultado da introduçăo do Programa Nacional do Alcool (Prod́lcool). Vários estudos anteriores (Veiga Filho et al., 1981; Egler 1985; Homen de Melo 1982) têm examinado impactos da canavização tanto no Centro-Sul como no Nordeste após o advento do Proálcool. Aqui procura-se aprimorar e testar uma metodologia para estudar a reorganizaçăo do espaço agrícola paraibano no período compreendido desde a implantaçăo do Proálcool até nossos dias. O estudo destaca-se pelo método utilizado: em vez da utilização de dados de micro-regióes, optou-se por utilizar os dados mais desagregado disponiveis aqueles ao nivel municipal. $O$ estudo limita-se aos municipios que apresentam atividade canavieira minimamente significante em termos de área cultivada do município e direcionada para a produçăo de açúcar/álcool. ${ }^{1}$

A recente expansáo canavieira e alcooleira na Paraíba esiá indisoluvelmente ligada ao avanço do Proálcool, de cuja história faz parte e da qual devem ser relembrados determinados aspectos. A utilizaçăo de fontes alternativas de energia tem constituido um desafio constante ao longo das últimas seis décadas. No início dos anos 70 , a conjuntura internacional favorável para o mercado açucareiro levou o Governo a acelerar a modernizaçăo do setor sucro-alcooleiro. Foram, entáo, criados o Programa de Racionalizaçăo da Agro-indústria Açucareira e o Programa Nacional de Melhoramento da Cana-de-Açúcar - Planalsucar, que possibilitaram o estabelecimento de um sistema integrado, visando - desenvolvimento do setor e a elevação da competitividade do açúcar brasileiro no exterior. Com a retraçăo da demanda internacional de açúcar, a partir de 1975, o setor açucareiro entra numa conjuntura adversa. Era necessário encontrar uma maneira de salvar a indústria sucro-alcooleira da crise que se abatia sobre o setor. A crise do petróleo também vinha tendo um impacto negativo sobre o balanço de pagamentos do país. Confluindo estes fatores, os usineiros, a partir de então, passaram a ver com bons olhos a instauração de um programa governamental para produzir álcool a

1) Neste sentido foi excluida da análise a area interiorana do Sertăo Paraibano, cuja reduzida produção de cana-de-açúcar está destinada a outros fins: rapadura, forragem para gado, etc. 
ser utilizado como combustivel de veículos automotores. Os empresários, tanto do setor sucro-alcooleiro como do setor de equipamentos para usinas e destilarias, deram total apoio a um programa que utilizaria álcool como fonte alternativa de energia.

A priorização da produção de álcool carburante, em paralelo aos interêsses do setor empresarial e às dificuldades da nação, explicam a implantação, em 1975, do Programa Nacional do Alcool - Proálcool. Este se insere na mesma filosofia modernizante que presidia as reestruturaçóes comandadas pelo Estado na agroindústria açucareira desde a segunda metade dos anos 60. Assim, novos projelos foram desenvolvidos visando:

a) o aperfeiçoamento do motor a álcool;

b) a assistência técnica à produção de cana-de-açúcar, mandioca e outras matérias-primas para fins energéticos;

c) a modernização e ampliação de destilarias autônomas;

d) a implantaçăo ou modernizaçăo de destilarias anexas às antigas usinas.

Essas medidas viabilizaram o avanço qualitativo e quantitativo da agro-indústria açucareira e, em especial, alcooleira, a partir de 1976. O álcool foi o maior responsável pelo crescimento da agroindústria canavieira nacional. Na primeira década do Proálcool, sua produção cresceu a uma taxa anual de $35 \%$, elevando-se de cerca de 0,6 milhões de litros na safra $1975 / 76$ para 11,8 milhōes na de 1985/86.

O Proálcool atingiu seu principal objetivo quanto ao uso do álcool como combustivel substituto em veículos automotores, resultando na diminuição da importação de petróleo, e até transformando o Brasil em exportador de gasolina. Ao mesmo tempo, alterou a configuração do agro e converteu o setor açucareiro numa verdadeira agro-indústria canavieirosucro-alcooleira.

O Proálcool representa uma tentativa de dinamizar/revitalizar não só uma parte do setor agrícola brasileiro como também dinamizar o setor industrial na medida em que a capitalização do setor agricola geraria uma demanda para as indústrias químicas de fertilizantes, indústrias de máquinas e implementos agricolas, indústrias fabricantes de destilarias, etc. 


\section{II - As três grandes fases do Proálcool}

O Proálcool atravessa momentos distintos, que acreditamos poder agrupar em três grandes fases diferenciadas, que dão conta de sua gênese, auge e, finalmente, declínio rumo à estagnação ou à sua provável extinção. São elas, ao nosso entender, as seguintes:

$1^{\text {a }}$ fase: 1975-80, quando se institucionalizam os incentivos do Programa e quando se montam destilarias anexas às usinas, modernizando-se simultaneamente as já existentes; implantam-se destilarias autônomas e expandem-se consideravelmente as plantações de cana-de-açúcar, com direcionamento para áreas sem tradiçăo canavieira;

2 fase: 1981-85, de grande avanço, como desdobramento da aprovação do protocolo entre os empresários do setor automobilístico e o Governo, em 1979, que determinava a produção massiva de veículos automotores a álcool. Foi implantado um grande número de destilarias autônomas em áreas "nãotradicionais", acelerando, por conseguinte, sua canavização. O PROALCOOL atingiu seu objetivo principal no que se refere ao uso do álcool como combustível substituto, resultando na diminuição da importação de petróleo. Ao mesmo tempo, alterou a configuração do agro, convertendo esse setor numa verdadeira agro-indústria canavieiro-sucroalcooleira.

$3^{\text {a }}$ fase: 1986 ao presente, ainda năo claramente definida, de grande instabilidade e com futuro imprevisível. 


\section{III - O crescimento moderado da produção paraibana de açúcar}

Em 1975, como resultado da crise que se abatia sobre o setor sucro-alcooleiro após a queda dos preços internacionais e da evoluçáo do contexto da política açucareira nacional, o IAA determina a contenção da quota de exportação de açúcar e passa a apoiar substancial e aceleradamente a produçăo de álcool como medida de defesa do setor canavieiro. A efetivaçăo deste objetivo fol resultado direto dos incentivos fornecidos ao setor, que viabilizou simultaneamente a modernizaçăo das usinas para a ampliaçăo da produçẳo de açúcar e a implantação/ampliaçăo/modernizaçăo das destilarias para a fabricaçáo do álcool. Estas mudanças representaram um marco na produçăo alcooleira nacional e paraibana, afetando a produção de açúcar, como se verá a seguir.

Analizando os dados da Tabela I pode-se constatar que a produçăo de açúcar na Paraíba, no decorrer das saf́ras 1971/72 1986/87, apresentou uma moderada mas nítida tendência crescente, que apesar de algumas oscilaçбes relativamente bruscas de um ano para o outro $(-15 \%,+40 \%)$, pode resumir-se a uma taxa de crescimento cumulativa em torno de $2,5 \%$ ao ano. As oscilaçóes da produçăo açucareira parecem dever-se mais aos impulsos do mercado (cotaçăo dos preços internacionais) do que ao eventual efeito da demanda por cana para álcool, a produçăo alternativa à de açúcar. No período 1985-87, a quantidade de canade-açúcar produzida pela Paraíba representou a média de aproximadamente $4 \%$ da produçăo total do Brasil.

\section{IV - A expansão das destilarias e do álcool na Paraíba}

O álcool anidro utilizado para mistura com a gasolina já era produzido na Paraíba no final da década de 1920, na usina Mandacarú, em Joăo Pessoa, que utilizava equipamentos construídos pela indústria Skoda, da Tchecoslováquia. Esta usina tinha uma capacidade de produçăo de 10.000 litros/dia. Em 1927/28 existiam oito usinas com turbina e vácuo no Estado da Paraiba. Durante o inicio dos anos trinta estavam em operaçăo as usinas Sant'Ana, Santa Maria, São Gonçalo, Santa Rita, Săo Joăo, Tanques e Santa Helena. 
TABELA 1.

Produção de açúcar no Estado da Paraíba, segundo a safra agrícola $1972 / 73$ a $1986 / 87$.

\begin{tabular}{|c|ccc|}
\hline $\begin{array}{c}\text { safra } \\
\text { (jul./jun.) }\end{array}$ & $\begin{array}{c}\text { usinas } \\
\text { No }\end{array}$ & $\begin{array}{c}\text { produção } \\
\text { ton }\end{array}$ & $\begin{array}{c}\text { variação anual } \\
\%\end{array}$ \\
\hline $1971 / 72$ & 7 & 89.951 & \\
$1972 / 73$ & 7 & 96.507 & 7,9 \\
$1973 / 74$ & 7 & 95.840 & 0,7 \\
$1974 / 75$ & 7 & 110.775 & 15,6 \\
$1975 / 76$ & 7 & 92.214 & 15,0 \\
$1976 / 77$ & 7 & 131.759 & 39,9 \\
$1977 / 78$ & 7 & 136.897 & 3,9 \\
$1978 / 79$ & 7 & 120.334 & 12,1 \\
$1979 / 80$ & 7 & 125.181 & 4,0 \\
$1980 / 81$ & 7 & 131.619 & 5,1 \\
$1981 / 82$ & 7 & 120.917 & $-1,1$ \\
$1982 / 83$ & 7 & 146.741 & 21,4 \\
$1983 / 84$ & 7 & 152.223 & 3,7 \\
$1984 / 85$ & 7 & 151.722 & - \\
$1985 / 86$ & 7 & 153.619 & 1,3 \\
$1986 / 87$ & 7 & 130.305 & $-15,2$ \\
\hline
\end{tabular}

Fonte: Instituto do Açúcar $\theta$ do Alcool, Escritório de Representação na Paraíba.

Data também deste período a produçăo de álcool-motor na Paraiba, geralmente uma mistura de álcool com gasolina e em alguns casos com querozene. No periodo de 1932 a 1937, a Paraiba produziu 111.881 litros de álcool-motor utilizando 106.109 litros de álcool, com um percentual de 94,84 de álcool na mistura. 


\section{TABELA 2.}

Produção de álcool (anidro e hidratado) de cana-de-açúcar na Paraíba, com especificaçăo do número de destilarias em funcionamento, segundo a safra agrícola - 1971/72-1989/90.

\begin{tabular}{|c|ccc|}
\hline $\begin{array}{c}\text { safra } \\
\text { (jul./jun.) }\end{array}$ & $\begin{array}{c}\text { destilarias } \\
\mathrm{N}^{0}\end{array}$ & $\begin{array}{c}\text { produçáo } \\
\mathrm{m}^{3}\end{array}$ & $\begin{array}{c}\text { variação anual } \\
\%\end{array}$ \\
\hline $1971 / 72$ & 4 & 5.040 & - \\
$1972 / 73$ & 3 & 3.805 & $-24,5$ \\
$1973 / 74$ & 3 & 2.218 & $-41,7$ \\
$1974 / 75$ & 3 & 1.392 & $-37,2$ \\
& & & \\
$1975 / 76$ & 2 & 806,8 & $-42,1$ \\
$1976 / 77$ & 1 & 57.4 & $-92,9$ \\
$1977 / 78$ & 4 & 18.112 & $31.453,8$ \\
$1978 / 79$ & 6 & 41.457 & 128,9 \\
$1979 / 80$ & 8 & 67.010 & 61,6 \\
$1980 / 81$ & 7 & 74.337 & 10,9 \\
$1981 / 82$ & 8 & 75.338 & 1,4 \\
$1982 / 83$ & 10 & 158.713 & 110,7 \\
$1983 / 84$ & 10 & 167.713 & 5,7 \\
$1984 / 85$ & 11 & 229.319 & 36,7 \\
& & & \\
$1985 / 86$ & 12 & 310.155 & 35,3 \\
$1986 / 87$ & 13 & 300.177 & $-3,2$ \\
$1987 / 88$ & 14 & 285.364 & $-4,9$ \\
$1988 / 89$ & 14 & 276.224 & $-3,2$ \\
$1989 / 90$ & 13 & 283.561 & 2,7 \\
$1990 / 91^{*}$ & 13 & 264.674 & - \\
\hline
\end{tabular}

Fonte: Instituto do Açúcar e do Alcool, Escritório de Representaçăo na Paraiba.

Obs.: Os dados para o ano civil obviamente diferem dos aqui apresentados. Por ex., o IAA reporta, para a Paralba, uma produção de 64.090 .000 I em 1979, 81.274.000 I em 1980 e 82.168.0001 em 1981. (IAA, Relatório/81, p. 25).

": Dados provisórios, posiçăo em abril/1991. 
QUADRO 1.

Usinas e destilarias da Paraiba, com especificação da localização e do grupo de controle acionário - 1991 .

\begin{tabular}{cllll|}
\hline usina/destilaria & municipio & microrregião & grupo econômico \\
\hline usinas & 1. Monte Alegre & Mamanguape & Litoral Paraibano & Soares de Oliveira \\
de acúcar & 2. Tanques & Alagoa Grande & Piemonte da Borborema & Veloso Borges \\
\hline usinas com & 3. Santa Helena & Sapé & Agro-Pastoril & Ribeiro Coutinho \\
destilaria & 4. Santa Maria & Areia & Brejo Paraibano & Solon Lins \\
anexa & 5. Santana & Santa Rita & Litoral Paraibano & Ribeiro Coutinho \\
& 6. Santa Rita & Santa Rita & Litoral Paraibano & Ribeiro Coutinho \\
& 7. São João & Santa Rita & Litoral Paraibano & Ribeiro Coutinho \\
\hline destilarias & 8. Arthur Tavares & Pedras de Fogo & Litoral Paraibano & Tavares de Melo \\
autónomas & 9. Borborema & Pirpirituba & Brejo Paraibano & Ribeiro Coutinho \\
& 10. Jacuipe & Santa Rita & Litoral Paraibano & José Ivanildo \\
& 11. Japungú & Santa Rita & Litoral Paraibano & José Ivanildo \\
& 12. Miriri & Sapé & Agro-Pastoril & José Ivanildo \\
& 13. Santo Antônio & Mataraca & Agro-Pastoril & Pessoa de Melo \\
& 14. Tabú & Caaporã & Litoral Paraibano & Lundgren \\
& 15. UNA & Sapé & Agro-Pastoril & Pessoa de Queiroz (PE) \\
& 16. Xuá & Mamanguape & Litoral Paraibano & João Furtado (ENARQ) \\
\hline
\end{tabular}


Até 1976/77, o álcool foi no Estado um sub-produto do processo de fabricaçáo do açúcar, sendo produzido apenas nas destilarias anexas às usinas. A partir dessa safra passou a ser também produzido diretamente da cana-de-açúcar. Com o Proálcool surgiram várias destilarias autônomas e procedeu-se à implantaçăo e ampliação de outras anexas, principalmente no último terço da década de 70 e primeira metade da de $80 .^{2}$ Ao todo, enquanto no início dos anos 70 apenas 3 destilarias anexas produziam álcool, a Paraiba conta hoje com 7 usinas de açúcar, das quais 5 possuem destilarias anexas, e com 9 destilarias autônomas.

Os dados da Tabela II indicam que na Paraíba somente a partir da safra de $1977 / 78$ a produção do álcool toma maior vulto, ultrapassando então os 18 milhóes de litros. Nesta safra existiam apenas quatro destilarias de álcool, sendo duas anexas às usinas Santa Helena e Săo Joăo e duas autônomas, a Arthur Tavares e a Miriri. Mais de $70 \%$ dessa produção do álcool era proveniente da destilaria Arthur Tavares. Em 1988, a Paraiba contava com 13 destilarias das 375 existentes no país, ou seja, 3,5\% do total.

\section{V - A expansão dos canaviais}

As usinas, de um modo geral, impulsionadas pelas injeçóes dadivosas do novo surto modernizador, passaram a implementar as novas técnicas na unidade industrial e a demandar quantidades crescentes de cana-de-açúcar. Mas o incremento fundamental por cana veio das destilarias autônomas. Em consequência, os plantadores expandiram de modo incisivo suas atividades, e o cultivo da cana-de-açúcar registrou uma expansão notável em têrmos quantitativos (área) bem como qualitativos (novos tipos de terra e novas variedades).

2) Até o dia 31/12/1981, a Paralba tinha 13 projetos enquadrados no Proálcool: 3 de destilarias anexas, com capacidade de produção de 23,7 milhoes de litros/safra, e 10 de destilarias autónomas, com capacidade de produçáo de 200,6 milhóes de litros/safra, totalisando 13 projetos de destilarias, com capacidade de produçăo global de 224,3 milhós de litros/safra. Os projetos da Paralba representavam $2,8 \%$ da capacidade do conjunto de projetos enquadrados em todo o pals, e $3,1 \%$ do total dos investimentos aprovados. 
Não só nas várzeas, áreas tradicionais da lavoura canavieira, mas também nos tabuleiros costeiros, áreas tradicionalmence consideradas pouco favoráveis a essa cultura, expandiram-se os canaviais, com bons rendimentos agricolas. ${ }^{3}$

Conforme tradicionalmente apontado, na Paraiba a área canavieira situa-se nas micro-regióes homogêneas Litoral Paraibano (MRH No 93), Piemonte da Borborema (92), AgroPastoril do Baixo Paraiba (99) e Brejo Paraibano (98). Destas, a micro-região do Litoral Paraibano tem na agro-indústria a sua base econômica.

Enquanto as destilarias anexas estāo localizadas nas áreas tradicionalmente produtoras de cana-de-açúcar, as destilarias autônomas situam-se em áreas conquistadas pela expansão da lavoura canavieira. Esta conquista deu-se em áreas anteriormente ocupadas pela pequena lavoura e/ou pela criação extensiva.

A delimitação e acompanhamento da área plantada com canade-açúcar feita através das Micro-regiōes Homogêneas é um tanto grosseira e imprecisa. A possibilidade da "municipalização" da especificação da área canavieira, baseada nos dados da Produção Agricola Municipal, abre novas perspectivas e sugere uma redefinição da área com cana-de-açúcar.

\section{VI - A (re)deffinição da "zona canavieria"}

Um dos objetivos deste trabalho é identificar a zona canavieira do Estado da Paraíba antes e cerca de 10 anos após a criação do Proálcool. As possibilidades de acompanhamento das

3) Em relação à existência de duas diferentes demandas por cana-de-açúcar, Egler (1985: 9 e 13) assinala: "A ocupação dos tabuleiros com vastas plantaçōes homogêneas de cana-de-açúcar preservou as antigas áreas canavieiras da competição pelo fornecimento de matéria-prima para as moendas. Assim as destilarias, em vez de se oporem as usinas como estas o fizeram aos engenhos no passado, acabam por justapor uma estrutura moderna a outra já obsoleta sem que haja conflito de interesses. Desta maneira, as várzeas permanecem sob controle das usinas, que procuram criar uma destilaria anexa às instalaçōes já existentes; enquanto os tabuleiros constituem área preferencial para o estabelecimento dos canaviais energéticos e das destilarias autônomas." 
transformações da área canavieira podem trazer novas luzes aos estudos relativos a esses espaços.

É importante frisar que a zona canavieira é habitualmente delimitada apenas em têrmos de micro-regiôes homogêneas (MRH) ou de um grupo reduzido de municipios principais ou geográficamente delimitados, geralmente recorrendo-se a indicadores absolutos de área colhida (e/ou cultivada) ou de volume de produção da cana-de-açúcar.

Os diversos estudos existentes, em geral, tratam a questão de duas formas principais: seja com demasiada agregação espacial (as inconvenientes MRHs), seja de modo parcial e seletivo, colocando apenas fatos e argumentos de alguns municípios que ilustram notoriamente, no fim das contas dirigidamente, a tese que se quer demonstrar.

A delimitação por MRH é de manipulação fácil, devido ao número reduzido destas micro-regióes, e é empregado para estudos do tipo macro. No nosso entendimento, seu elevado nível de agregação pode englobar situaçōes muito dissímiles, ocultando mais do que revelando (por compensação de diferenças) realidades importantes. Assim, mudanças na produçăo de cana ocoridas numa determinada micro-região não nos revelam em quais municipios ocorreram tais mudanças e se decréscimos em alguns municípios foram compensados por acréscimos em outros municipios da mesma micro-região, parecendo à primeira vista que não houve mudanças no interior da mesma, as quais podem ter efetivamente ocorrido, com consequências substanciais.

Pelas razōes expostas, para uma análise mais acurada nāo há como evitar a utilização das estatisticas mais precisas disponiveis: os dados a nivel municipal. Estes são fornecidos em duas versões: os dados dos censos agricolas e as estimativas da Produção Agrícola Municipal (PAM), ambos publicados pelo IBGE. Nós entendemos que os que melhor refletem a realidade săo as estimativas da PAM, que se referem a economia canavieira municipal real, em contraste com os dados dos censos agrícolas realizados a cada 5 anos, cujas informaçóes referem-se ao conjunto dos estabelecimentos agro-pecuários efetivamente recenseados e não ao total dos existentes. 
Esta metodologia tem por objetivo determinar melhor a verdadeira configuraçăo da zona conavieira, resultante do processo de canavização.

Preliminarmente, se faz necessário explicitar as categorias com as quais trabalharemos:

- zona canavieira: consiste no conjunto de "municípios canavieiros". A zona canavieira sub-divide-se, conforme - grau de intensidade da cultura canavieira nos municípios canavieiros, em área central canavieira (coeficiente de intensidade $\geq 10 \%$ e periferia canavieira (coeficiente de intensidade $\geq 2 \%$ e $<10$ $\%)^{4}$.

- municípios canavieiros: são aqueles com um índice de canavização (indice de área canavizada)., por nós tipificados como tendo um coeficiente de intensidade da atividade canavieira superior a $10 \%$ da área total do município colhida com cana-de-açúcar.

- fronteira canavieira: cinturão que delimita a zona canavieira, separando os municípios conquistados pela cana-de-açúcar dos municípios (ainda) não canavieiros.

O Coeficiente de Intensidade será calculado de acordo com a seguinte formula:

$$
c_{\mathbf{j}}=\text { área com cana / área total } \times 100
$$

O coeficiente de intensidade indica a importância da produção de cana-de-açúcar em cada um dos vários municípios, com especificacão do nivel da atividade canavieira. Utilizando uma média

4) Qualquer corte que for feito para separar em grupos os municipios conforme o coeficiente de intensidade aqui calculado, será mais ou menos arbitrário. Devido à năo existência de parâmetros consensuais nem intevalos de áreas claramente diferenciados, optou-se aqui pelos valores de 2, 5,10 e $20 \%$ (agrupados pela sua vez em duas categorias maiores), que além de fornecer uma primeira idéia da situação da qual devem dar conta, presta-se também a comparações estatísticas com os resultados de outros trabalhos devido a que a divisão aqui empregada corresponde-se aos valores dos intervalos empregados pelo IBGE nos seus levantamentos estatisticos e aos geralmente utilizados pelos pesquisadores. 
referente a um triênio para o cálculo da área com cana minimizaremos o problema dos efeitos conjunturais da sazonalidade agrícola e económica, assim como das variaçóes climáticas em cada um deles. A área total corresponde à de cada município (sempre e quando não tenham experimentado alterações geográficoadministrativas).

A zona canavieira antes do Proálcool a chamaremos de zona canavieira tradicional e a zona canavieira identificada após o Proálcool a denominaremos de nova zona canavieira. Esta nova zona engloba a zona canavieira tradicional mais as nova áreas de expansão da cana após o Proálcool, diminuindo as áreas que porventura tenham deixado a atividade.

A melhor opção de operacionalização provavelmente é usar, para fins de comparação e de identificação da zona canavieira tradicional para cada município, o período-base do triênio 1974 76, que inicia com o primeiro ano em que começa uma série coerente (já sob responsabilidade do IBGE) da PAM, e termina com o último ano em que o Programa, decretado em final de 1975, ainda năo deixa sentir seus efeitos, principalmente nos indicadores de área, que à época referiam-se a área colhida ${ }^{5}$. Esse periodo-base (1974-76) é possivel compará-lo com periodos posteriores, particularmente com os índices médios de intensidade da atividade canavieira correspondente aos triênios 1979-81 e 1984-86. Utilizando as médias para determinar a intensidade da cultura canavieira nos diversos municípios, em cada um dos triênios escolhidos, reduzir-se-á o problema da sazonalidade. $O$ indice de intensidade média da cultura escolhida (cana-de-açúcar), é calculado como a média aritmética dos três anos do triênio correspondente da razão entre a área colhida com cana-de-açúcar e a área total do município.

Este método identificará superficies concêntricas. Separando a "zona canavieira tradicional" da "nova zona canavieira" está a "velha fronteira canavieira". Entre a "zona canavieira" global, em particular a "periferia canavieira", e o cordão de municípios limítrofes está a "nova fronteira canavieira".

5) E não mais a área cultivada, como era habitual nas estatísticas nacionais até 1965. 
Esquema de representação gráfica das áreas da ZC conceitualmente propostas

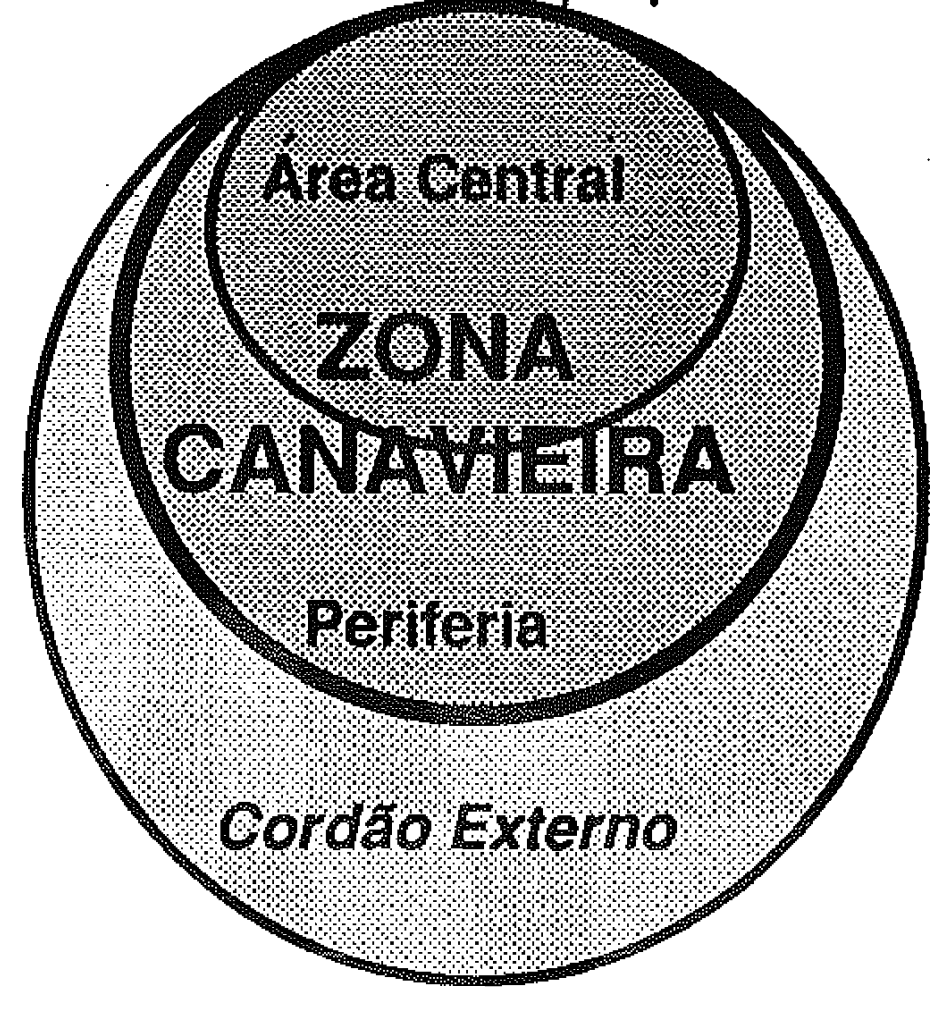

O resultado pode ser primeiro ilustrado em um esquema gráfico, obtendo-se diversos niveis de intensidade que podem ser separados conforme a conveniência analítico-operacional.

\section{VII - Análise dos resultados para a Paraíba}

No Estado da Paraíba, procede-se ao confronto dos indicadores (índices médios de intensidade da atividade canavieira) relativos:

1 ) ao periodo-base (1974-76) aqui referido como 1975 e considerado como o período pré-Proálcool,

2 ) ao triênio 1979-81, aqui tratado como 1980 e relativo ao período de auge do Proálcool, e

3 ) ao triênio 1984-86, aqui referido como 1985. 
Dessa análise comparativa entre os diversos períodos significativos para os objetivos aqui colocados, surgem algumas características destacáveis:

- Na Paraíba, a intensidade da cultura canavieira, medida através da área colhida com cana-de-açúcar em relaçăo ao total da área do Estado, tem aumentado paralelamente ao avanço do Proálcool. Isto é perceptível através da comparação dos coeficientes de intensidade para o Estado, que elevaram-se de $1,1 \%$ em 1975 para $1,9 \%$ em 1980 e para 3,0\% em 1985. Este desempenho representa taxas de mudança de $79 \%$ de acréscimo para o primeiro intervalo $1975-80$ e de $57 \%$ para o periodo $1980-85$.

- O exame do comportamento desses mesmos indicadores para as 4 microrregiбes homogêneas - MRH (Litoral Paraibano, Piemonte da Borborema, Brejo Paraibano e Agro-Pastoril da Paraíba), que são consideradas zradicionalmente como as microrregióes homogêneas canavieiras, revela um aumento mais acentuado dos coeficientes de intensidade: de $6.0 \% \mathrm{em}$ 1975 para $11,1 \%$ em 1980 e para $17,7 \%$ em 1985 . Este quadro representa taxas de mudança de $86 \%$ de acréscimo para o interstício $1975-80$ e de $60 \%$ para o intervalo 1980-85.

- É notório que o mesmo cálculo feito acima, baseado nos dados do Estado da Paraíba e do conjunto das $4 \mathrm{MRH}$ tradicionalmente consideradas como canavieiras, demonstra que a análise, no caso particular da Paraíba, não apresenta diferenças relevantes nem substanciais. Isto porque para os períodos examinados, 1975-80 e 1980-85, os indicadores da taxa de variação aumentaram, respectivamente, $79 \%$ e $57 \%$ para todo o Estado e $86 \%$ e $60 \%$ para o conjunto dessas $4 \mathrm{MRH}$. Esta constatação indica que ao passar do nivel de agregaçăo estadual para o nivel de agregação microrregional, a precisão não necessariamente aumenta de maneira substancial de modo a permitir a verificação das transformaç̧̋es internas a cada uma dessas MRH e às quatro em conjunto. quando não há homogeneidade básica (nos limites da tolerância do bem senso e da Estatística), é indispensável uma análise mais desagregada. 
- A abordagem analítica ao nivel municipal, no caso da Paraiba aqui estudado considerando 47 municipios de 4 $\mathrm{MRH}$, mostra claramente comportamentos totalmente dispares de um município a outro dentro de cada uma das 4 $\mathrm{MRH}$ acima aludidas. Pudemos identificar quatro grupos de municípios dentro destas $4 \mathrm{MRH}$ :

1) municípios tradicionalmente canavieiros que tiveram expansão significativa da atividade canavieira, como săo os casos de 8 municípios: Alagoinha, Cruz do Espírito Santo, Juripiranga, Piloes, Santa Rita, São Miguel de Taipú, Sapé e Serraria.

2) municípios tradicionalmente náo-canavieiros que registraram um aprofundamento significativo da atividade canavieira, como são os casos de 13 municípios: Alhandra, Itapororoca, Jacarau, Lucena, Mari, Mataraca, Pedras de Fogo, Pilar, Pirpirituba e Pitimbú, bem como os de Caaporá, Cuitegi e. Mamanguape, que já apresentavam um índice razoável de atividade canavieira.

3) municípios tradicionalmente canavieiros que mantiveram seu nivel de atividade canavieira, como são os casos de 5 municípios: Alagoa Grande, Alagoa Nova, Areia, Borborema e Pilóezinhos.

4 ) municipios tradicionalmente não-canavieiros (ausência de canaviais ou baixa atividade canavieira) que náo registraram mudanças ou um aprofundamento significativo da atividade canavieira, como săo os casos de 21 municípios: Araçagi, Baia da Traiçăo, Bayeux, Belém, Caiçara, Caldas Brandăo, Conde, Duas Estradas, Guarabira, Gurinhem, Ingá, Itabaiana, João Pessoa, Lagoa de Dentro, Mogeiro, Mulungú, Rio Tinto, Salgado de São Felix, São Sebastião de Lagoa de Roça e Serra da Raiz, e mesmo um município com desempenho irregular como é o de Bananeiras.

- O comportamento destes 4 grupos de municípios é revelador:

1) os municipios tradicionalmente canavieiros que tiveram expansão significativa da atividade canavieira, 
passaram de 16,9\% em 1975 para $26,0 \%$ em 1980 e para 38,5\% em 1985.

2) os municípios tradicionalmente năo-canavieiros que registraram um aprofundamento significativo da atividade canavieira, passaram de $3,2 \%$ em 1975 para $12,6 \%$ em 1980 e para $26,9 \%$ em 1985.

$3)$ os municipios tradicionalmente canavieiros que mantiveram seu nivel de atividade canavieira, passaram de $17,5 \%$ em 1975 para $19,3 \%$ em 1980 e para $17,6 \%$ em 1985 .

4 ) os municipios tradicionalmente não-canavieiros (ausência de canaviais ou baixa atividade canavieira) que não registraram mudanças ou um aprofundamento significativo da atividade canavieira, passaram de $0,8 \%$ em 1975 para 2,0\% em 1980 e para 1,7\% em 1985.

- Observa-se que em cada um destes 4 grupos de municípios estão incluidos municípios pertencentes às $4 \mathrm{MRH}$ tradicionalmente consideradas como canavieiras.

\section{VIII - Conclusões}

O estudo mostra a importância de se trabalhar ao nivel mais desagregado possivel permitido pela disponibilidade dos dados. Mostra também que conclusōes tiradas a nivel elevado de agregaçăo (estadual e mesmo microrregional) podem mascarar processos de mudança mais do que revelar os verdadeiros processos ocorridos no interior dessas totalidades.

Os dados revelam que a agregaçăo por microrregióes não estabelece com nitidez suficiente processos de mudança homogêneos. Os processos de canavizaçăo, estagnação da cultura ou eventual declínio se espalham por todas as microrregióes consideradas sem que as fronteiras destas microrregiбes sirvam de diferencial perfeito para previsões do que nelas ocorre.

Assim, o presente trabalho aponta para a necessidade de trabalhar a nivel municipal para que não se cometa (ou ao menos para diminuir substancialmente a probabilidade de que isso venha a acontecer) a célebre falácia ecológica, ou seja, ao se observar um 
incremento de cultura de cana-de-açúcar e, p. ex., um decréscimo na produção de alimentos, se concluir uma relaçăo de causalidade quando os dois fenômenos podem ter acontecido dentro de espaços municipais completamente diferentes.

Finalmente, o fato de se verificar a existência de tendências paralelas ou mesmo uma correlação estatística, náo pode ser considerado como suficiente para extrair conclusóes de causalidade. Devem ser examinados todos os falôres múltiplos que intervieram no processo real e que podem ser, em maior ou menor grau, coresponsáveis pelos resultados observados.

\section{IX - Bibliografia}

"Açúcar e Álcool", revista Indústria \& Produtividade, Rio de Janeiro, abril/1985.

COMISSÃo EXECUTIVA NACIONAL dO ÁLCOOL (CENAL), Programa

Nacional do Álcool. Relatório Anual. (Vários números.)

EGLER, Cláudio Antônio G., "Os impactos do PROÁLCOOL na Paraiba", GEONORDESTE, Ano II, № 1, 1985.

IBGE, Anuário Estatísicico do Brasil, Rio de Janeiro, IBGE, anos 1964/1990.

IBGE, Produção Agrícola Municipal da Paraiba. Rio de Janeiro, IBGE, anos 1974/1989.

MELO, Fernando Bento Homen de, "A produçăo de biomassa e o crescimento da área cultivada no Brasil", Revista Brasileira de Tecnologia, vol. 13, № 1, jan.-mar./1982. Ministério da Indústria e do Comércio / Instituto do Açúcar e do Alcool, Relatório Anual do IAA. Anos de 1974, 1975, 1976, 1977, 1978, 1979, 1980, 1981, 1982, 1983.

SZMRECSANYI, Tamás, O Planejamento da Agroindústria Canavieira do Brasil (1930-1975). Săo Paulo, .Ed. Hucitec/Universidade Estadual de Campinas, 1979.

VEIGA FILHO, Alceu Arruda; Elcio Umberto Gatti \& Nilda Tereza Cardoso de Mello, "O Programa Nacional do Álcool e seus impactos na agricultura paulista", Estudos Econômicos, edição especial № 61-62, 1981. 


\section{QUADRO 1}

Area cohida com cana-de-açúcar, por municipio, Microrregiăo e Estado, 1974-1989, com especificaçáo do total de área, média de área, intensidade municipal e variaçăo de intensidade, nos períodos $1974 / 76,1979 / 81$ e $1984 / 86$.

\begin{tabular}{|c|c|c|c|c|c|c|c|c|}
\hline \multirow[b]{2}{*}{$\begin{array}{c}\text { Hicroregioes } \\
\text { Municlplos }\end{array}$} & \multicolumn{8}{|c|}{ area colhida com cana de-acúcar } \\
\hline & $\begin{array}{c}1974 \\
\text { ha. }\end{array}$ & $\begin{array}{c}1975 \\
\text { ha. }\end{array}$ & $\begin{array}{c}1976 \\
\text { ha. }\end{array}$ & $\begin{array}{c}1977 \\
\text { ha. }\end{array}$ & $\begin{array}{c}1978 \\
\text { ha. }\end{array}$ & $\begin{array}{c}1979 \\
\text { ha. }\end{array}$ & $\begin{array}{c}1980 \\
\text { ha. }\end{array}$ & $\begin{array}{c}1981 \\
\mathrm{ha}_{1}\end{array}$ \\
\hline $\begin{array}{l}\text { Lhoral Paralbano } \\
\text { Alhandra }\end{array}$ & $\begin{array}{r}17140 \\
80\end{array}$ & $\begin{array}{r}21299 \\
900\end{array}$ & $\begin{array}{r}25379 \\
2634\end{array}$ & $\begin{array}{r}31240 \\
2500\end{array}$ & $\begin{array}{r}37434 \\
1278\end{array}$ & $\begin{array}{r}40662 \\
1500\end{array}$ & $\begin{array}{r}48768 \\
1503\end{array}$ & $\begin{array}{r}58433 \\
1750\end{array}$ \\
\hline Bala da Tralç5o & - & - & - & $=$ & 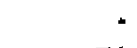 & - & $=$ & - \\
\hline Bayoux & 0 & 0 & 0 & 74 & 74 & 49 & 44 & 37 \\
\hline Caapora & 400 & 533 & 1053 & 1000 & 1965 & 1962 & 1965 & 2298 \\
\hline Conde & 30 & 33 & 6 & 8 & 70 & 45 & 46 & 53 \\
\hline Cruz do E Santo & 6418 & 8000 & 6534 & 6500 & 7366 & 7700 & 6510 & 10000 \\
\hline llapororoca & 130 & 200 & 210 & 205 & 1179 & 1500 & 1803 & 2160 \\
\hline Jacarau & 200 & 225 & 230 & 390 & 2063 & 1500 & 1652 & 1980 \\
\hline Joáo Passoa & 130 & 140 & 345 & 327 & 296 & 196 & 228 & 92 \\
\hline Lucena & 200 & 340 & 368 & 350 & 492 & 1200 & 1202 & 1800 \\
\hline Mamanguape & 3541 & 3066 & 3058 & 6172 & 5235 & 6500 & 7484 & 10455 \\
\hline Mataraca & 15 & 15 & 25 & 20 & 2947 & 3000 & 6007 & 6000 \\
\hline Pedras de Fogo & 1200 & 2204 & 2530 & 3900 & 3891 & 5000 & 7209 & 9600 \\
\hline Plimbú & 33 & 13 & 24 & 25 & 492 & 180 & 180 & 220 \\
\hline Rlo Tinto & 120 & 130 & 142 & 233 & 787 & 800 & 921 & $128 B$ \\
\hline Santa Rlta & 6535 & 7500 & B 220 & 9530 & 9359 & 9530 & 10014 & 10500 \\
\hline Plemonte da Borb. & 6822 & 0065 & 11018 & 11246 & 10029 & 10515 & 9100 & 8710 \\
\hline Alagoa Grande & 4416 & 5600 & 6696 & 6000 & 5892 & 6200 & 4960 & 4950 \\
\hline Alagoinha & 700 & 1000 & 1135 & 1600 & 1277 & 1300 & 1300 & 1300 \\
\hline Aracagl & 300 & 350 & 34 & 350 & 354 & 365 & 380 & 200 \\
\hline Belém & 200 & 200 & 341 & 500 & 295 & 300 & 300 & 300 \\
\hline Calcaya & 10 & 20 & 23 & 30 & 30 & 30 & 30 & 30 \\
\hline Cuthagl & 250 & 250 & 454 & 400 & 393 & 400 & 300 & 300 \\
\hline Duat Estradas & 10 & 15 & 17 & 15 & 25 & 25 & 30 & 30 \\
\hline Guarablra & 500 & 1100 & 1248 & 1100 & 491 & 500 & 370 & 360 \\
\hline Gurinhem & 110 & 100 & 250 & 600 & 589 & 600 & 700 & 420 \\
\hline Ingáa & - & . & 23 & 20 & 20 & 20 & 20 & 20 \\
\hline Lagos de Daniro & 20 & 25 & 26 & 25 & 25 & 25 & 25 & 30 \\
\hline Mulungs & 0 & 0 & 0 & 140 & 137 & 240 & 250 & 250 \\
\hline Plloezinhos & 300 & 300 & 454 & 460 & 491 & 500 & 500 & 500 \\
\hline Serca da Ralz & 5 & 6 & 7 & 6 & 10 & 10 & 15 & 20 \\
\hline Brejo Paralbano & 12902 & 14050 & 16220 & 16470 & 23470 & 23966 & 26200 & 25240 \\
\hline Alagoa Nova & 1700 & 1700 & 1700 & 2050 & 2259 & 2500 & 2000 & 1200 \\
\hline Arola & 4592 & 5200 & 5500 & 5500 & 5401 & 9500 & 4400 & 4240 \\
\hline Bananelras & 500 & 550 & 1129 & 1700 & 2946 & 3000 & 3100 & 3100 \\
\hline Borborema & 400 & 450 & 450 & 450 & 589 & 640 & 700 & 700 \\
\hline Pllbes & 3000 & 3000 & 4200 & 4700 & 5401 & 5500 & 5500 & 5500 \\
\hline PIrplrituba & 100 & 150 & 250 & 800 & 2946 & 2046 & 3000 & 3000 \\
\hline Sáo Sob. Lg. Roga & 0 & 0 & 0 & 0 & 0 & 0 & 0 & 0 \\
\hline Serrarla & 2700 & 3000 & 3000 & 3270 & 3928 & 4000 & 7500 & 7500 \\
\hline Agro.Paglorll & 9908 & 11210 & 14000 & 95700 & 17312 & 18600 & 19500 & 24500 \\
\hline Caldas Brandso & 100 & 100 & 130 & 600 & 589 & 600 & 600 & 600 \\
\hline llabalana & 100 & 50 & 20 & 20 & 196 & 200 & 200 & 200 \\
\hline Jurlplranga & 2600 & 2600 & 4000 & 4000 & 3732 & 3800 & 4000 & 5000 \\
\hline Mart & 250 & 200 & 250 & 1730 & 1699 & 2000 & 2000 & 2300 \\
\hline Mogelro & - & $=$ & - & - & - & - & . & \\
\hline Pllar & 560 & 560 & 600 & 600 & 589 & 600 & 1000 & 1200 \\
\hline Salgado de S. Felix & - & - & . & • & - & - & - & \\
\hline S. Moguol do Taipu & 1000 & 700 & 2000 & 2000 & 2160 & 2200 & 2200 & 3200 \\
\hline Sapo & 5298 & 7000 & 7000 & 6898 & B 347 & 9200 & 9500 & 12000 \\
\hline Paralba & 51600 & $60 \mathrm{O45}$ & 70407 & 80159 & 91964 & 97490 & 107376 & $120 \quad 932$ \\
\hline
\end{tabular}




\begin{tabular}{|c|c|c|c|c|c|c|c|}
\hline \multicolumn{8}{|c|}{ area colhida com cana-de-açucar } \\
\hline $\begin{array}{c}1982 \\
\text { ma. }\end{array}$ & $\begin{array}{c}1983 \\
\text { ha. }\end{array}$ & $\begin{array}{c}1984 \\
\text { ha. }\end{array}$ & $\begin{array}{c}1985 \\
\text { ha. }\end{array}$ & $\begin{array}{c}1986 \\
\mathrm{ha} \\
\end{array}$ & $\begin{array}{c}1987 \\
\text { ha. }\end{array}$ & $\begin{array}{c}1988 \\
\mathrm{ha}\end{array}$ & $\begin{array}{c}1989 \\
\mathrm{ha}\end{array}$ \\
\hline 69679 & 83096 & 97350 & 107135 & 108729 & 105967 & 104238 & 504362 \\
\hline 4060 & 4060 & 4060 & 4060 & 4060 & 2600 & 600 & 600 \\
\hline$=$ & $\dot{-}$ & $\cdot$ & - & $\cdot$ & $=$ & 200 & 200 \\
\hline 17 & 17 & 17 & 17 & 17 & 15 & 10 & 10 \\
\hline 4000 & 4008 & 4008 & 4006 & 5000 & 5000 & 6000 & 6000 \\
\hline $\mathbf{5 3}$ & $\mathbf{5 3}$ & 153 & 510 & $5 \neq 0$ & 510 & 510 & 510 \\
\hline 11000 & 11500 & 11600 & 11600 & 11700 & 11700 & 11000 & 10900 \\
\hline 2160 & 2500 & 2800 & 3100 & 3200 & 3200 & 3200 & 3200 \\
\hline 2400 & 2020 & 4200 & 4400 & 4400 & 4400 & 4400 & 4400 \\
\hline 80 & 80 & 50 & 50 & 50 & 50 & 50 & 50 \\
\hline 1800 & 1800 & 1800 & 1800 & 1000 & 1000 & 1800 & 1900 \\
\hline 12000 & 12700 & 13500 & 14000 & 14300 & 14000 & 14000 & 14000 \\
\hline 7035 & 7342 & 7342 & 7792 & 7792 & 7792 & 7792 & 7792 \\
\hline 10700 & 13000 & 13500 & 30000 & 30000 & 30000 & 30000 & 30000 \\
\hline 1080 & 1500 & 1630 & 2000 & 2000 & 2000 & 2000 & 2000 \\
\hline 1280 & 1038 & 2700 & 3500 & 3500 & 3500 & 3500 & 500 \\
\hline 12000 & 20000 & 20000 & 20300 & 20300 & 20300 & 19078 & 19300 \\
\hline 9300 & 750 & 9710 & 9060 & 10010 & 9155 & 9660 & 9044 \\
\hline 5610 & 5100 & 5100 & 4250 & 5000 & 5000 & 5500 & 5700 \\
\hline 1300 & 1500 & 2000 & 2000 & 2500 & 2000 & 2000 & 2000 \\
\hline 200 & 200 & 300 & 300 & 300 & 300 & 300 & 300 \\
\hline 300 & 300 & 300 & 300 & 300 & 200 & 200 & 200 \\
\hline 30 & 40 & 30 & 30 & 30 & 5 & 10 & 4 \\
\hline 300 & 200 & 700 & 700 & 800 & 800 & 800 & 60 \\
\hline 30 & 30 & so & 50 & 50 & 50 & 50 & 50 \\
\hline 360 & 350 & 400 & 400 & 400 & 300 & 300 & 300 \\
\hline 400 & 190 & 60 & 60 & 80 & 80 & 00 & 60 \\
\hline 20 & $=$ & - & - & $=$ & - & - & . \\
\hline 30 & 30 & 50 & 50 & 50 & 50 & 50 & 50 \\
\hline 200 & 200 & 100 & 300 & 120 & 70 & 70 & 70 \\
\hline 500 & 500 & 500 & 500 & 300 & 200 & 200 & 150 \\
\hline 20 & 120 & 120 & 120 & 100 & 100 & 100 & 100 \\
\hline 26010 & 18730 & 214 的 & 21010 & 22700 & 16950 & 17420 & 19520 \\
\hline 1360 & 1360 & 1360 & 1360 & 1700 & 1200 & 1300 & 1300 \\
\hline 5100 & 5520 & 5520 & 5950 & 6500 & 6000 & 6500 & 6000 \\
\hline 3100 & 300 & 400 & 300 & 300 & 50 & $\$ 0$ & 150 \\
\hline 750 & 350 & 500 & 500 & 500 & 100 & 70 & 70 \\
\hline 5500 & 5700 & 5700 & 5700 & 5700 & 5000 & 5000 & 4500 \\
\hline 3000 & 3000 & 3000 & 3000 & 3000 & 2500 & 2500 & 2500 \\
\hline 0 & 0 & 0 & 0 & 0 & 0 & 0 & 0 \\
\hline 8000 & 2500 & 5000 & 5000 & 5000 & 2000 & 2000 & 5000 \\
\hline 26000 & 31070 & $35 \quad 128$ & 36240 & 34480 & 27060 & 26860 & 23220 \\
\hline 100 & 200 & 180 & 120 & 220 & 200 & 100 & ह0 \\
\hline 200 & 370 & 800 & 600 & 600 & 600 & 1500 & \& 300 \\
\hline 5000 & 5000 & 5500 & 5600 & 5600 & 6000 & 8000 & 5500 \\
\hline 4000 & 4800 & 4800 & 800 & 3000 & 3000 & 3000 & 3000 \\
\hline- & $=$ & - & - & $=$ & - & $\cdot$ & 100 \\
\hline 1200 & 2500 & 2500 & 2500 & 2500 & 1700 & 1700 & 1700 \\
\hline & - & 48 & 60 & 60 & 60 & 60 & 60 \\
\hline 3200 & 3200 & 3500 & 3500 & 3500 & 3500 & 3500 & 3500 \\
\hline 12300 & 15000 & 18000 & 19000 & 19000 & t2 000 & 10600 & 0000 \\
\hline 134655 & 149799 & 155700 & 176201 & 170077 & 162266 & 150229 & 158762 \\
\hline
\end{tabular}




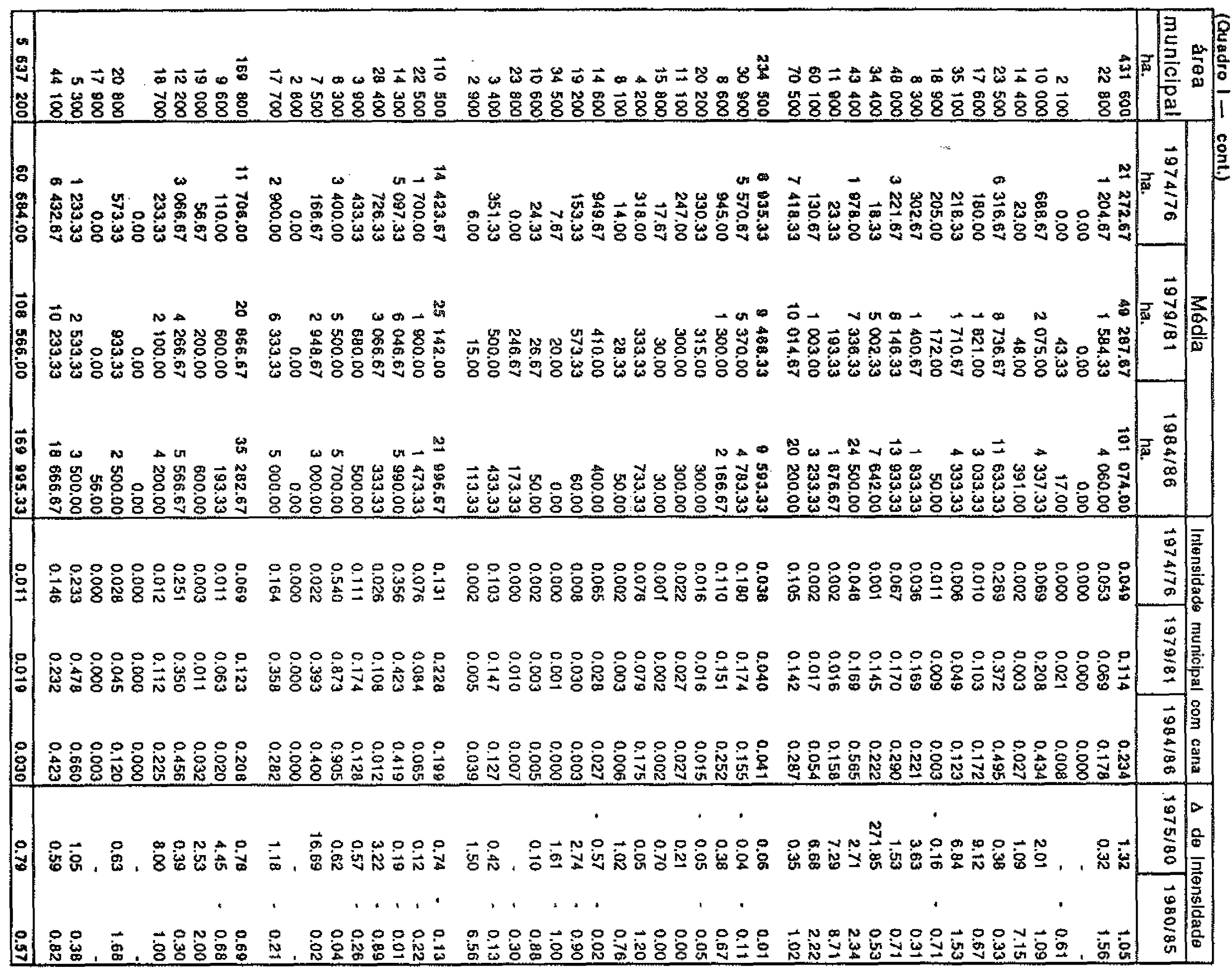

